\title{
Nonlinear Simulation of Pre-Darcy Flow in CQZS Super-Low Permeability Reservoir
}

\author{
Qing-yan $\mathrm{XU}^{*}$ \\ Research Institute of Petroleum Exploration \& \\ Development \\ Beijing ,China \\ E-mail: xuqingyan007@163.com \\ Cong WU \\ Research Institute of Petroleum Exploration \\ \&Development, \\ Huabei Oilfield Branch \\ Renqiu, China \\ E-mail: 31658861@qq.com
}

\author{
Rong-liang GUAN \\ Daqing NO. 1 Drilling Company .Daqing Drilling Ltd. \\ Daqing, China \\ E-mail: guanrong1984@126.com
}

\begin{abstract}
A newly developed nonlinear flow numerical software was used to make a research for the Pre-Darcy flow of CQZS super-low permeability reservoir. The results show that: the nonlinear seepage dominates in a large scale of formation; under the conditions of present well pattern, the residual oil saturation is high and water flooding fails to spread to most regions which induce bad development effect and ineffective driving pressure system; then nine adjustment cases are designed and according to the development comparison of different cases, convert and infill can both improve the effect of development. At last, development effect comparison is carried on and the best case is selected.
\end{abstract}

Keywords-super-low permeability; Pre-Darcy flow; nonlinear seepage; numerical simulation

\section{INTRODUCTION}

In this paper, a newly developed nonlinear flow numerical simulator is used to make an integrated numerical simulation study on CQZS super-low permeability reservoir. By means of precise depicted oilfield geological parameters and history matching, accurate geological model can be established and residual oil distribution could be analyzed. Besides, different schemes of well pattern adjustment and infill plans are designed. Significantly, the flow regions are divided by the reservoir pressure gradient distributions of different cases to evaluate the reservoir producing degree and the well pattern adaptability. As to each case, development effect of the future 20 years will be forecasted and evaluated. This can provide scientific basis for the future rational development and important reference for other similar reservoirs.

\section{ESTABLISHMENT OF FIELD MODEL}

Typical seepage curve of super-low permeability reservoirs includes no flow section, nonlinear percolation bending section and quasi-linear seepage section. In order to describe the nonlinear flow curve of super-low permeability reservoir in mathematical manner, experimental modification is used on the basis of classical Darcy's law. The equation of the motion in the super-low permeability reservoir and mathematical model can be referenced in the related references ${ }^{[1-5]}$.

CQZS super-low permeability reservoir lies in the structural position of Daan-Honggang syncline slope belt. There is a reverse normal fault to the west of the block and the type of the reservoir is fault-lithologic. The major bed series for development is Fuyu oil bed of Quan4 section whose sandstone thickness is $100-120 \mathrm{~m}$. The average sandstone thickness and net thickness of single well drilled is $30.50 \mathrm{~m}$ and $10.05 \mathrm{~m}$ respectively. Twelve layers are divided in vertical direction. The major layers are layer3, layer5, layer6, layer10. Diamond inverted nine-spot well pattern is adopted in this block. At present, the well pattern is $500 \mathrm{~m} \times 150 \mathrm{~m}$. The average porosity is 0.108 with a range $0.07-0.14$, and the average permeability is $0.44 \mathrm{mD}$ with a range of $(0.06-2.20)$ $\mathrm{mD}$. Water injection begins at March 2006, and all the injected wells are put into work until July 2006. The oil wells start to produce at January 2007.

According to the laboratory core experiment data, the real threshold pressure gradient is $0.02 \mathrm{MPa} / \mathrm{m}$, the pseudo threshold gradient is $0.04 \mathrm{MPa} / \mathrm{m}$ and the critical threshold pressure gradient is $0.2 \mathrm{MPa} / \mathrm{m}$. According to nonlinear percolation experiment, the nonlinear seepage parameters can be obtained. On the basis of the model, history matching is conducted and fairly good result is obtained. Under the conditions of present well pattern, the residual oil saturation is high and water flooding fails to spread to most regions which induce bad development effect and ineffective driving pressure system. Residual oil saturation in the block is high and most area of reservoir stratum is not swept by the water drive. The injected water only spread to the small area in the vicinity of water injection well and on the contrary the region far from the injection wells is not swept. The pressure gradient in the reservoir is very small and most belongs to the nonlinear 
bending section. Nonlinear percolation area takes up a large proportion and the driving effect is poor. In other words, effective driving system is not established. Therefore, adjustment should be adopted.

\section{Adjustment Model Design}

Converting the diamond inverted nine-spot well pattern to five-spot well pattern by converting the corner production well to injection well is a commonly used well adjustment method, which is called convert here. Well infill which add one oil well between two original oil wells on the oil wells row is also considered, which is called infill. In view of the existing well pattern, nine cases are designed to predict the development effect for the next twenty years.

Case 1: no adjustment is adopted; Case 2: convert at once; Case 3: convert after 5 years' regular production on the basis of existing well pattern; Case 4: convert after 10 years' regular production on the basis of existing well pattern.

Case 5: infill at once, Case 6: infill and convert at once.

Case 7: infill at once butconvert after 1 years' regular production on the basis of existing well pattern.

Case 8: infill at once butconvert after 2 years' regular production on the basis of existing well pattern.

Case 9: infill at once butconvert after 5 years' regular production on the basis of existing well pattern.

As showed in Table 1, the first case is the worst one. Among the three convert cases (case 2-4), case 2 displays the best development. Among the five convert combined with infill cases (case 5-9), case 6 shows the best development.

In conclusion case 6 is the best according to comparison of cumulative oil and increased oil.

\section{CONCLUSIONS}

On the basis of nonlinear simulation, most pressure gradient in the formation without adjustment belongs to nonlinear seepage bending section during the development of super-low permeability reservoirs. Nonlinear percolation area takes up a large proportion and dominates in the flow. Under present well pattern, the residual oil saturation in the block is high and most area of reservoir stratum is not swept by the water drive. Several adjustment plans enhance the oil recovery in different degrees. The earlier to conduct the well conversion, the higher oil recovery will be gained. The combination of conversion and infill can get the best result.

TABLE 1. CONTRAST OF DIFFERENT SCHEMES RESULT

\begin{tabular}{ccccc}
\hline & $\begin{array}{c}\text { Cumulative } \\
\text { oil } \\
\text { (MSTB) }\end{array}$ & $\begin{array}{c}\text { Cumulative } \\
\text { increased oil } \\
\text { (MSTB) }\end{array}$ & $\begin{array}{c}\text { Oil } \\
\text { recovery } \\
\text { rate } \\
(\%)\end{array}$ & $\begin{array}{c}\text { Water } \\
\text { cut } \\
(\%)\end{array}$ \\
\hline Case1 & 1122 & 0 & 14.25 & 85.16 \\
Case 2 & 1380 & 258 & 17.52 & 88.64 \\
Case 3 & 1348 & 226 & 17.11 & 87.54 \\
Case 4 & 1296 & 174 & 16.46 & 85.59 \\
Case 5 & 1149 & 27 & 14.59 & 85.78 \\
Case 6 & 1429 & 307 & 18.15 & 90.39 \\
Case 7 & 1418 & 296 & 18.00 & 90.13 \\
Case 8 & 1410 & 288 & 17.90 & 89.93 \\
Case 9 & 1385 & 263 & 17.58 & 89.17 \\
\hline
\end{tabular}

\section{REFERENCES}

[1] Xu Q.Y., Liu X.G., Yang Z.M., Wang J. 2011. The model and algorithm of a new numerical simulation software for low permeability reservoirs. Journal of Petroleum Science and Engineering,78(2):239-242

[2] Yang Z.M., Zhang Y.Z., Hao M.Q, et al. 2006. Comprehensive evaluation of reservoir in low-permeability oilfields. Acta Petrolei Sinica, 27(2):64-67.

[3] Yang Z.M., Yu R.Z., Su Z.X., et al. 2010. Numerical simulation of the nonlinear flow in ultra-low permeability reservoirs. Petroleum Exploration and Development, 37(1):94-98

[4] Yu R.Z., Lei Q., Yang Z.M., et al. 2010. Nonlinear flow numerical simulation of an ultra-low permeability reservoir. Chinese Physics Letters, 27(7):074702(1-4)

[5] Yu R.Z, Bian Y.N., Yang Z.M., et al. 2010. Numerical simulation of variable permeability of low-permeability porous media. Science \& Technology Review 28(20):29-33. 